\title{
Reflexão sobre os riscos ocupacionais que a equipe de enfermagem estar exposta:
}

\section{Uma revisão de literatura}

\author{
Reflection on the occupational risks that the nursing team may be exposed to: A literature review \\ Reflexión sobre los riesgos laborales a los que puede estar expuesto el equipo de enfermería:
}

Revisión de la literatura

Recebido: 09/11/2021 | Revisado: 18/11/2021 | Aceito: 22/11/2021 | Publicado: 23/11/2021

\author{
Keitianne Aquino Santos \\ ORCID: https://orcid.org/0000-0002-5409-1564 \\ Universidade CEUMA, Brasil \\ E-mail: keitiannesantos@hotmail.com \\ Benedita Maryjose Gleyk Gomes \\ ORCID: https://orcid.org/0000-0002-5231-3936 \\ Universidade CEUMA, Brasil \\ Andiara Casimiro Bonfim Miranda \\ ORCID: https://orcid.org/0000-0002-2465-4223 \\ Universidade CEUMA, Brasil \\ E-mail: andiara_asimiro@hotmail.com \\ Cristina Limeira Leite \\ ORCID: https://orcid.org/0000-0002-7321-1496 \\ Universidade CEUMA, Brasil \\ E-mail: crislimeira@gmail.com
}

\begin{abstract}
Resumo
A saúde dos trabalhadores, principalmente os que atuam na área da saúde, como a equipe de enfermagem, são peças importantes e essenciais para a vida dentro da sociedade, os orgãos de saude, juntamente com suas equipes que estão na linha de frente precisam proprocionar boas condições de trabalho a essa população. A problemática em questão consiste em descobrir os riscos ocupacionais que os profissionais de saúde estão expostos durante a jornada de trabalho. Nesse sentido, o objetivo desse estudo foi analisar e discutir riscos ocupacionais que profissionais de saúde estão expostos durante a jornada de trabalho. A pesquisa consiste numa revisão bibliográfica, estando aliada as informações pertinentes a Biblioteca Virtual em Saúde (BVS), Literatura Latino-Americana em Ciências de Saúde (LILACS), Scientific Eletronic Library Online (SCIELO) Medline. Os principais resultados encontrados puderam mostrar os riscos que os profissionais de saúde estão expostos nos locais de trabalho, ou seja, esse profissional está sujeito a adquirir ou desenvolver doenças de ordem física, química, biológica, ergonômica, e de acidentes. Ficando claro, que os trabalhadores que atuam no ambiente hospitalar, lidam diariamente com a exposição diária aos agentes causadores de adoecimento. Logo, os profissionais da enfermagem acabam sendo o público mais afetado, e consequentemente aquele que tem maiores chances de adquirir doenças especificas do trabalho, devido ser o profissional que lida diariamente com os pacientes.
\end{abstract}

Palavras-chave: Riscos ocupacionais; Qualidade de vida; Trabalhador; Políticas públicas.

\begin{abstract}
The health of workers, especially those working in the health area, such as the nursing team, are important and essential pieces for life within society, the health agencies, along with their teams that are on the front lines, need to provide good working conditions for this population. The issue in question is to discover the occupational risks that health professionals are exposed to during the working day. In this sense, the objective of this study was to analyze and discuss occupational risks that health professionals are exposed to during their working hours. The research consists of a literature review, with relevant information being combined with the Virtual Health Library (VHL), Latin American Literature on Health Sciences (LILACS), Scientific Electronic Library Online (SCIELO) Medline. The main results found could show the risks that health professionals are exposed to in the workplace, that is, these professionals are subject to acquiring or developing physical, chemical, biological, ergonomic, and accident-related illnesses. It is clear that workers who work in the hospital environment deal daily with daily exposure to diseasecausing agents. Therefore, nursing professionals end up being the most affected public, and consequently the one with the greatest chances of acquiring specific work-related illnesses, as they are the professionals who deal with patients on a daily basis.
\end{abstract}

Keywords: Occupational hazards; Quality of life; Worker; Public policy. 


\begin{abstract}
Resumen
La salud de los trabajadores, especialmente los que laboran en el área de la salud, como el equipo de enfermería, son piezas importantes y esenciales para la vida en la sociedad, las agencias de salud, junto con sus equipos que están en primera línea, necesitan brindar buenas condiciones de trabajo. para esta población. Se trata de conocer los riesgos laborales a los que están expuestos los profesionales sanitarios durante la jornada laboral. En este sentido, el objetivo de este estudio fue analizar y discutir los riesgos laborales a los que están expuestos los profesionales de la salud durante su jornada laboral. La investigación consiste en una revisión de la literatura, combinándose información relevante con la Biblioteca Virtual en Salud (BVS), Literatura Latinoamericana en Ciencias de la Salud (LILACS), Biblioteca Electrónica Científica en Línea (SCIELO) Medline. Los principales resultados encontrados podrían mostrar los riesgos a los que están expuestos los profesionales de la salud en el lugar de trabajo, es decir, estos profesionales están sujetos a adquirir o desarrollar enfermedades físicas, químicas, biológicas, ergonómicas y relacionadas con accidentes. Es evidente que los trabajadores que trabajan en el entorno hospitalario se enfrentan a diario a la exposición diaria a agentes causantes de enfermedades. Por tanto, los profesionales de enfermería acaban siendo el público más afectado y, en consecuencia, el que tiene mayores posibilidades de adquirir enfermedades específicas relacionadas con el trabajo, ya que son los profesionales que atienden a los pacientes en el día a día.
\end{abstract}

Palabras clave: Riesgos laborales; Calidad de vida; Trabajador; Políticas públicas.

\title{
1. Introdução
}

A saúde dos trabalhadores, principalmente os que atuam na área da saúde, como a equipe de enfermagem, são peças importantes e essenciais para a vida dentro da sociedade, os orgãos de saude, juntamente com suas equipes que estão na linha de frente precisam proprocionar boas condições de trabalho a essa população. No entanto, para se fazer presente essas condições, é de suma importância que sejam cumprida, o que determina as políticas públicas voltada a saúde dos trabalhadores, e assim eliminar ou reduzir, os inúmeros desafios encontrados dentro dos ambientes de saúde, desde a sua infraestrutura, até a capacitação dos profissionais (Carmo; Tasso; Masson, 2016).

Estudos em torno os problemas de saúde ocasionados pelo trabalho, somente teve relância e ganhou espaço no cenário ocupacional em meados dos anos 40, nesse período o olhar sobre as doenças ocupacionais e às questões ligadas a qualidade de vida o trabalho, começaram a ganhar importância, ocasião essa que começou-se a se ter a compreensão sobre a necessidade de ações voltadas a prevenção e a manutenção da qualidade de vida no trabalho (Carvalho et al., 2017).

Carvalho et al., (2017) refere-se ao processo saúde adoecimento do trabalhador, como a resposta quanto as condições advindas das condições de trabalho e da resposta dessas condições, a saúde dos trabalhadores. A $8^{a}$ Conferência Nacional de Saúde (1986), definiu a saúde como resultado de vários pontos relevantes, entre eles: alimentação, habitação, educação, meio ambiente, trabalho, lazer e acesso aos serviços de saúde entre outros.

Dentre os locais de trabalho que mais oferece risco a saúde dos trabalhadores, estar os estabelecimentos de saúde, onde os profissionais que ali trabalham, conviem diariamente aos diversos riscos, proveniente do ambiente e da atividade laboral realizada. Nesse ambiente, os profissionais de enfermagem, são os que mais sofrem com os acidentes de trabalhos, por motivos relacionado as atividades desenvolvidas por estes. Dentre as atividades desenvolvidas pela equipe de enfermagem, destaca-se: a exposição direta a agentes infectantes, como agulhas e seringas, além de objetos contaminados, além do contato direto com o paciente potencializa os riscos (Arantes et al., 2017).

Os principais riscos encontrado nos locais de trabalhos, são: fisico, quimico, ergonomico, biologico e de acidentes. Dependendo do ambiente de trabalho, podemos encontrar um, ou varios riscos. Pode-se entender que, os riscos são situações que ocorrem de forma inadequada, seja pelo provocado como: máquinas, produtos químicos, ruídos ou a sobrecarregação de trabalho, quando não se usa os Equipamentos de Proteção Individual e dentre outros elementos que podem ocasioar prejuízos graves a saúde do profissional (Leite et al., 2016; da Silva, 2021).

Em se tratando do ambiente hospitalar, encontramos todos os riscos presente nesse ambiente, devido a diversidade de procedimentos ali realizado. Logo, os profissionais de enfermagem, estão expostos a vários riscos ocupacionais. Tais fatores, fazem com que o profissional tenha mais suscetibilidade em desenvolver doenças ocupacionais, é relevante que seja realizado 
ações no sentido de promover ações visando a redução desses riscos no ambiente de trabalho, para que tais índices sejam minimizados, onde os profissionais da saúde, consigam desempenhar bem suas funções além de ter qualidade de vida (Leite $e t$ al., 2016; Gregório, 2017; da Silva, 2021).).

Nesse viés, o objetivo do presente estudo, consiste em descrever os riscos ocupacionais que profissionais de saúde estão expostos durante a jornada de trabalho. E os objetivos específicos são: identificar quais são os principais riscos ocupacionais que afetam o profissional da área da saúde e levantar as principais medidas de proteção à saúde do trabalhador da saúde. A problemática em questão consiste em descobrir os riscos ocupacionais que profissionais de saúde estão expostos durante a jornada de trabalho.

Observa-se que a temática em questão é de grande importância para investigar os principais motivos que provocam os riscos que os profissionais de saúde estão expostos. Onde, diante dos resultados, espera-se contribuir com os interessados no tema, profissionais de saúde e gestores das unidades de Saúde, visando contribuir para promover uma maior divulgação do assunto, bem como trazer a luz uma problemática vivenciada pelos trabalhadores da saúde que vivenciam diariamente com os riscos ocupacionais.

\section{Metodologia}

Este estudo, estar pautado numa pesquisa bibliográfica desenvolvida através do método da Revisão Integrativa. Gil (2019, p. 55) diz que "a pesquisa bibliográfica pode ser conceituada como a ação de ler, realizar a seleção, fichamento e arquivamento de informações com conteúdo inerentes a nova pesquisa". A problemática em questão consiste em descobrir os riscos ocupacionais que profissionais de saúde estão expostos durante a jornada de trabalho.

Os dados foram obtidos nas seguintes bases de dados: Biblioteca Virtual em Saúde (BVS), Literatura LatinoAmericana em Ciências de Saúde (LILACS), Scientific Eletronic Library Online (SCIELO) e Medline. A investigação foi realizada fazendo uso do cruzamento das palavras-chave: Riscos Ocupacionais. Qualidade de vida. Trabalhador. Políticas Públicas. Os critérios de inclusão utilizados para a seleção da amostra foram: artigos publicados no período de 2015 a 2020 , escritos no idioma português, disponível na integra e que abordasse a temática em questão. Foram excluídos: artigos duplicados, não disponível na íntegra, fora do período escolhido para o estudo e escritos em outros idiomas. Sendo assim, segue Figura 1, apresentando o fluxograma com os resultados obtidos a partir das buscas.

Figura 1 - Fluxograma.

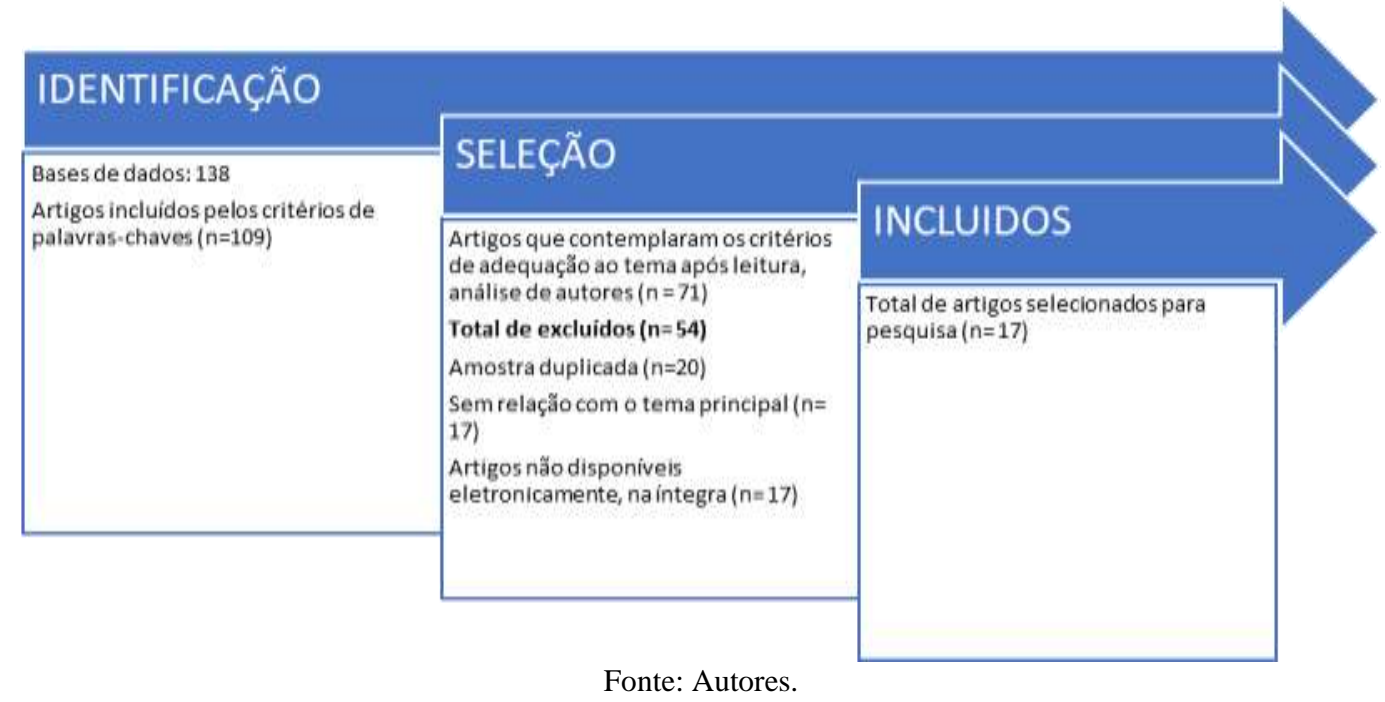

O total de artigos encontrados nas bases de dados foram 378 periódicos. Após a aplicação do filtro, chegou-se a 347 
artigos. Depois da leitura do resumo, restaram 319 artigos, no entanto após a aplicação dos critérios de inclusão e exclusão os que preenchiam a todos os critérios propostos totalizaram em 17 artigos.

\section{Resultados e Discussão}

Amostra das informações coletadas contemplam 20 (vinte) artigos científicos. Esse quadro apresenta todos os trabalhos selecionados, seguindo: anos de publicação; periódico; autores; título, tipo de pesquisa e principais resultados. No Quadro 1 são mostrados aos artigos levantados para revisão integrativa da literatura:

Quadro 1 - Artigos levantados para revisão integrativa da literatura.

\begin{tabular}{|c|c|c|c|c|c|}
\hline Ano & Periódico & Autores & Título & $\begin{array}{l}\text { Tipo de } \\
\text { pesquisa }\end{array}$ & Principais resultados \\
\hline 2016 & $\begin{array}{l}\text { Revista } \\
\text { Ciência \& } \\
\text { Inovação }\end{array}$ & $\begin{array}{l}\text { Carmo, T. A. } \\
\text { Do., Tasso, C. } \\
\text { A. S.., } \\
\text { Masson, V. A. }\end{array}$ & $\begin{array}{l}\text { Assistência de } \\
\text { Enfermagem do do } \\
\text { Trabalho: Prevenção } \\
\text { de Doenças } \\
\text { Ocupacionais }\end{array}$ & $\begin{array}{l}\text { Estudo } \\
\text { descritivo, } \\
\text { exploratório } \\
\quad \mathrm{e} \\
\text { retrospectiv } \\
\quad \mathrm{o}\end{array}$ & $\begin{array}{l}\text { O enfermeiro do trabalho atua na prevenção de } \\
\text { doenças ocupacionais por meio do } \\
\text { desenvolvimento de programas de proteção à saúde } \\
\text { do trabalhador. Avalia e desenvolve programas de } \\
\text { prevenções de acidentes e de doenças profissionais } \\
\text { divulgando conhecimentos, orientando a adoção de } \\
\text { comportamentos saudáveis, para promoção da } \\
\text { saúde e prevenção de doenças ocupacionais. }\end{array}$ \\
\hline 2017 & $\begin{array}{l}\text { Cogitare } \\
\text { Enferm }\end{array}$ & $\begin{array}{l}\text { Carvalho, D. } \\
\text { P. de., et el }\end{array}$ & $\begin{array}{l}\text { Cargas de trabalho e a } \\
\text { saúde do trabalhador } \\
\text { de enfermagem: } \\
\text { revisão integrativa }\end{array}$ & $\begin{array}{l}\text { Revisão } \\
\text { integrativa }\end{array}$ & $\begin{array}{l}\text { as cargas de trabalho causam prejuízos à saúde dos } \\
\text { trabalhadores de enfermagem, à instituição e à } \\
\text { assistência segura ao paciente. Assim, são } \\
\text { necessárias ações organizacionais, de prevenção de } \\
\text { acidentes e doenças relacionados ao trabalho, } \\
\text { visando à redução das cargas e à promoção da } \\
\text { saúde do trabalhador de enfermagem. }\end{array}$ \\
\hline 2020 & $\begin{array}{l}\text { Revista } \\
\text { Saúde }\end{array}$ & $\begin{array}{l}\text { Dias, C. V. P., } \\
\text { Damasceno, J. } \\
\text { C., Silva, L. } \\
\text { V. F., Rocha, } \\
\quad \text { B. M. }\end{array}$ & $\begin{array}{l}\text { Saúde do profissional } \\
\text { de } \quad \text { Enfermagem: } \\
\text { riscos ocupacionais } \\
\text { em r ambiente } \\
\text { hospitalar. }\end{array}$ & $\begin{array}{l}\text { Revisão da } \\
\text { Literatura }\end{array}$ & $\begin{array}{l}\text { Os riscos ocupacionais mais frequentes entre os } \\
\text { profissionais de enfermagem no período } 2009 \text { e } \\
2018 \text { segundo as literaturas selecionadas temos as } \\
\text { doenças osteomusculares e se nota desequilíbrios } \\
\text { psicológicos onde há o aparecimento de síndromes } \\
\text { como por exemplo a síndrome de burnout a qual } \\
\text { está em evidência entre os trabalhadores de } \\
\text { enfermagem. }\end{array}$ \\
\hline 2018 & $\begin{array}{l}\text { Ciência \& } \\
\text { Saúde } \\
\text { Coletiva }\end{array}$ & $\begin{array}{l}\text { Gomez, C. } \\
\quad \text { M., } \\
\text { Vasconcellos, } \\
\text { L. C. F. De., } \\
\text { Machado, J. } \\
\text { M. H. }\end{array}$ & $\begin{array}{l}\text { Saúde do trabalhador: } \\
\text { aspectos históricos, } \\
\text { avanços e desafios no } \\
\text { Sistema Único de } \\
\text { Saúde }\end{array}$ & $\begin{array}{l}\text { Revisão de } \\
\text { literatura }\end{array}$ & $\begin{array}{l}\text { Faz um breve balanço dos avanços e desafios diante } \\
\text { das transformações contínuas das condições e } \\
\text { formas de organização do trabalho e da limitada } \\
\text { efetividade das políticas de Estado para o } \\
\text { enfrentamento das condições de risco à saúde dos } \\
\text { trabalhadores. E, finalmente, aponta perspectivas de } \\
\text { que os avanços possíveis advêm de entrelaces dos } \\
\text { movimentos sociais e acadêmicos com conquistas } \\
\text { de espaços institucionais transformadores do } \\
\text { próprio SUS, recuperando sua essência } \\
\text { participativa e de promoção de saúde em uma visão } \\
\text { ampla de política de Estado. }\end{array}$ \\
\hline 2017 & $\begin{array}{l}\text { Id on Line } \\
\text { Rev. Psic. }\end{array}$ & $\begin{array}{l}\text { Gregório, D. } \\
\text { de S. }\end{array}$ & $\begin{array}{l}\text { Riscos } \text { Ocupacionais: } \\
\text { Uma revisão da } \\
\text { Literatura }\end{array}$ & $\begin{array}{l}\text { Revisão da } \\
\text { Literatura }\end{array}$ & $\begin{array}{l}\text { O profissional que trabalha em ambiente hospitalar } \\
\text { está exposto, não somente a acidentes de trabalho, } \\
\text { mas a desgaste mental e emocional. A sobrecarga } \\
\text { de trabalho por quantidade insuficiente de } \\
\text { profissionais e condições físicas inadequadas, tem } \\
\text { sido uma realidade que coloca em risco não apenas } \\
\text { o trabalhador, mas as pessoas envolvidas no } \\
\text { processo do cuidado. Tais situações compromete a } \\
\text { qualidade da assistência prestada. }\end{array}$ \\
\hline 2016 & $\begin{array}{c}\text { Enferm. } \\
\text { Foco }\end{array}$ & $\begin{array}{l}\text { Leite, H. D. } \\
\text { C. S., et el. }\end{array}$ & $\begin{array}{l}\text { Risco Ocupacional } \\
\text { entre profissionais de } \\
\text { saúde do Serviço de } \\
\text { Atendimento Móvel } \\
\text { de Urgência - SAMU }\end{array}$ & $\begin{array}{l}\text { Descritivo, } \\
\text { transversal }\end{array}$ & $\begin{array}{l}\text { O EPI mais utilizado foi o macacão, seguido das } \\
\text { luvas e máscaras. Os riscos a que mais se } \\
\text { submeteram foram: ruídos da sirene de ambulância, } \\
\text { colisão de carro, levantamento de maca, exposição } \\
\text { a sangue, poeira ambiental e estresse no } \\
\text { atendimento. }\end{array}$ \\
\hline
\end{tabular}




\begin{tabular}{|c|c|c|c|c|c|}
\hline 2020 & $\begin{array}{l}\text { Rev. } \\
\text { Interinst. } \\
\text { Bras. Ter. } \\
\text { Ocup }\end{array}$ & $\begin{array}{l}\text { Lopes, M. C., } \\
\quad \text { et el. }\end{array}$ & $\begin{array}{l}\text { Qualidade de vida de } \\
\text { profissionais atuantes } \\
\text { na área de reabilitação } \\
\text { de um hospital escola } \\
\text { no interior do Rio } \\
\text { Grande do Sul. }\end{array}$ & $\begin{array}{l}\text { Quantitativo } \\
\text {, descritivo }\end{array}$ & $\begin{array}{l}\text { A maioria. A maioria dos participantes mencionou } \\
\text { que foram diagnosticados com doenças } \\
\text { osteomusculares, ressalta-se que estas podem estar } \\
\text { relacionadas as condições de trabalho, sendo } \\
\text { resultantes de esforço repetitivo e más posturas } \\
\text { durante a jornada de trabalho. }\end{array}$ \\
\hline 2018 & $\begin{array}{l}\text { Revista } \\
\text { Eletrônica } \\
\text { Gestão \& } \\
\text { Saúde }\end{array}$ & $\begin{array}{l}\text { Marinho, T. } \\
\text { A., et al. }\end{array}$ &  & $\begin{array}{l}\text { Relato de } \\
\text { experiência }\end{array}$ & $\begin{array}{l}\text { Elementos associados aos riscos ambientais, saúde } \\
\text { mental e hábitos de vida dos trabalhadores } \\
\text { pesquisados causaram preocupação e foram pauta } \\
\text { da construção do processo ensino-aprendizagem na } \\
\text { formação dos discentes. }\end{array}$ \\
\hline 2017 & $\begin{array}{l}\text { Revista } \\
\text { Enfermage } \\
\quad \mathrm{m} \\
\text { Contempor } \\
\text { ânea. }\end{array}$ & $\begin{array}{l}\text { Oliveira, M. } \\
\text { M., Andrade, } \\
\text { N. V. de; } \\
\text { Brock, J. }\end{array}$ & $\begin{array}{l}\text { Riscos ocupacionais e } \\
\text { suas repercussões nos } \\
\text { profissionais de } \\
\text { enfermagem no } \\
\text { âmbito hospitalar. }\end{array}$ & $\begin{array}{l}\text { Revisão } \\
\text { integrativa }\end{array}$ & $\begin{array}{l}\text { A análise mostrou que a maneira como é } \\
\text { organizado o trabalho de enfermagem a nível } \\
\text { hospitalar bem como seu processo, são os maiores } \\
\text { causadores de exposição a riscos ocupacionais aos } \\
\text { trabalhadores, e como maior consequência dessa } \\
\text { exposição está o adoecimento seja físico ou } \\
\text { psíquico dos mesmos }\end{array}$ \\
\hline 2019 & $\begin{array}{l}\text { Brazilian } \\
\text { Journal of } \\
\text { Surgery and } \\
\text { Clinical } \\
\text { Research - } \\
\text { BJSCR. }\end{array}$ & $\begin{array}{l}\text { Oliveira, L. de } \\
\text { A. M., et al. }\end{array}$ & $\begin{array}{l}\text { Risco ocupacional em } \\
\text { profissionais médicos } \\
\text { e enfermeiros de } \\
\text { unidade de terapia } \\
\text { intensiva e suas } \\
\text { influências na } \\
\text { qualidade de vida: } \\
\text { uma revisão narrativa. }\end{array}$ & $\begin{array}{l}\text { Revisão } \\
\text { narrativa }\end{array}$ & $\begin{array}{l}\text { Os materiais perfuro- cortantes são os principais } \\
\text { responsáveis por acidentes ocupacionais, e isso } \\
\text { decore de técnicas incorretas e também da falta de } \\
\text { adesão às ações de biossegurança. Os riscos em } \\
\text { UTI estão relacionados não só a assistência ao } \\
\text { paciente, mas também ao ambiente laboral ao qual } \\
\text { o profissional está inserido que influencia } \\
\text { diretamente na qualidade de vida destes } \\
\text { profissionais. }\end{array}$ \\
\hline 2019 & $\begin{array}{l}\text { Arch } \\
\text { Health } \\
\text { Invest }\end{array}$ & $\begin{array}{l}\text { Pereira, J. P. } \\
\text { de M., } \\
\text { Nóbrega, W. } \\
\text { F. S., Paiva, } \\
\text { R. E. dos A. }\end{array}$ & $\begin{array}{l}\text { Doenças ocupacionais } \\
\text { em profissionais da } \\
\text { enfermagem: uma } \\
\text { revisão integrativa. }\end{array}$ & $\begin{array}{l}\text { revisão de } \\
\text { literatura }\end{array}$ & $\begin{array}{l}\text { As pesquisas apontam que os profissionais da } \\
\text { Enfermagem, devido exercerem uma profissão } \\
\text { peculiar em atribuições e local de trabalho, estão } \\
\text { diariamente expostos a diversos riscos que podem } \\
\text { resultar em doenças laborais. }\end{array}$ \\
\hline 2016 & $\begin{array}{l}\text { Revista } \\
\text { Brasileira } \\
\text { de Saúde } \\
\text { Ocupaciona } \\
\quad 1\end{array}$ & $\begin{array}{l}\text { Silva, A., } \\
\text { Ferraz, L., } \\
\text { Junior, S. A. } \\
\text { R. }\end{array}$ & $\begin{array}{lr}\text { Ações em Saúde } & \text { do } \\
\text { Trabalhador } & \\
\text { desenvolvidas } & \text { na } \\
\text { Atenção Primária } & \text { no } \\
\text { município } & \text { de } \\
\text { Chapecó, } & \text { Santa } \\
\text { Catarina } & \end{array}$ & $\begin{array}{l}\text { Estudo } \\
\text { descritivo } \\
\text { com } \\
\text { enfoque } \\
\text { qualitativo }\end{array}$ & $\begin{array}{l}\text { Mediante agendamento, as rotinas de trabalho na } \\
\text { Atenção Primária estão centradas em atendimentos } \\
\text { ao usuário e as ações desenvolvidas nos centros de } \\
\text { saúde contemplam apenas os Programas de Saúde } \\
\text { básicos. Entre as dificuldades enfrentadas para a } \\
\text { realização de ações em Saúde do Trabalhador, o } \\
\text { pouco conhecimento a respeito do tema se converte } \\
\text { em um forte argumento para justificar a própria } \\
\text { ausência dessas ações. }\end{array}$ \\
\hline 2020 & $\begin{array}{l}\text { Rev Bras } \\
\text { Enferm }\end{array}$ & $\begin{array}{l}\text { Silva, R. P., } \\
\text { Valente, G. S. } \\
\text { C., Camacho, } \\
\text { A. C. L. F. }\end{array}$ & $\begin{array}{l}\text { O gerenciamento de } \\
\text { risco no âmbito da } \\
\text { saúde de profissionais } \\
\text { de enfermagem no } \\
\text { contexto hospitalar }\end{array}$ & $\begin{array}{l}\text { Pesquisa } \\
\text { descritivo- } \\
\text { exploratória } \\
\quad \text { com } \\
\text { abordagem } \\
\text { qualitativa }\end{array}$ & $\begin{array}{l}\text { Identificou-se que os riscos no trabalho sofridos } \\
\text { pelos profissionais de enfermagem são diversos, } \\
\text { destacando-se a sobrecarga de trabalho pelo } \\
\text { número grande de pacientes ou número diminuto } \\
\text { dos profissionais, infraestrutura inadequada e } \\
\text { organização gerencial insuficiente. Em relação às } \\
\text { doenças ocupacionais, a maioria dos depoentes } \\
\text { relatou que sofre de algum tipo de patologia que } \\
\text { afeta a sua saúde, manifestando-se sob a forma de } \\
\text { ansiedades, noites mal dormidas, problemas } \\
\text { psicossomáticos, musculoesqueléticos etc. }\end{array}$ \\
\hline 2020 & $\begin{array}{l}\text { Enfermage } \\
\text { m Revista }\end{array}$ & $\begin{array}{l}\text { Silvério, F. C. } \\
\text { de M., } \\
\text { Moraes, R. S. } \\
\text { de. }\end{array}$ & $\begin{array}{l}\text { Enfermeiro } r \text { do } \\
\text { trabalho: prevenção } \\
\text { de riscos ergonômicos }\end{array}$ & $\begin{array}{l}\text { Revisão de } \\
\text { literatura }\end{array}$ & $\begin{array}{l}\text { destacou a importância do papel do enfermeirodo } \\
\text { trabalho para prevenção, promoção, e recuperação } \\
000000{ }^{\circ} \text { GCCCCCXXXdos } \\
\text { contribuindo na diminuição de acidentes laborais. }\end{array}$ \\
\hline 2015 & $\begin{array}{l}\text { Revista } \\
\text { Fafibe On- } \\
\text { Line }\end{array}$ & $\begin{array}{l}\text { Carrara, G. L. } \\
\text { R., } \\
\text { Magalhães, D. } \\
\text { M.., Lima, R. } \\
\quad \text { C. }\end{array}$ & $\begin{array}{l}\text { Riscos ocupacionais e } \\
\text { os agravos à saúde } \\
\text { dos profissionais de } \\
\text { enfermagem. }\end{array}$ & $\begin{array}{l}\text { Pesquisa } \\
\text { Bibliográfic } \\
\quad \text { a }\end{array}$ & $\begin{array}{l}\text { As publicações analisadas permitiram-nos concluir } \\
\text { que os principais riscos a que estão expostos os } \\
\text { profissionais de enfermagem no ambiente } \\
\text { hospitalar são: os acidentes, ergonômicos, } \\
\text { químicos, físicos e biológicos. }\end{array}$ \\
\hline
\end{tabular}




\begin{tabular}{|c|c|c|c|c|c|}
\hline 2018 & $\begin{array}{l}\text { Rev Bras } \\
\text { Med Trab }\end{array}$ & $\begin{array}{c}\text { Ferreira, A. } \\
\text { P., et al }\end{array}$ & $\begin{array}{l}\text { Revisão da literatura } \\
\text { sobre os riscos do } \\
\text { ambiente de trabalho } \\
\text { quanto às condições } \\
\text { laborais e o impacto } \\
\text { na saúde do } \\
\text { trabalhador }\end{array}$ & $\begin{array}{l}\text { Revisão da } \\
\text { literatura }\end{array}$ & $\begin{array}{l}\text { Os agravos à saúde do trabalhador apresentam-se } \\
\text { imbricados com diversos tipos de risco. Os } \\
\text { trabalhadores ficam sujeitos à exposição a aspectos } \\
\text { materiais, físicos, químicos, biológicos, culturais e } \\
\text { organizacionais nos processos de trabalho. Uma } \\
\text { abordagem integrada do ambiente de trabalho, } \\
\text { nesse sentido, propiciaria ações menos } \\
\text { fragmentadas, servindo de base para legislações e } \\
\text { políticas públicas que respeitem a realidade e a } \\
\text { dignidade do trabalhador }\end{array}$ \\
\hline 2020 & $\begin{array}{l}\text { Trabalho de } \\
\text { conclusão } \\
\text { de curso }\end{array}$ & $\begin{array}{l}\text { Xavier, E. K. } \\
\text { M., Gusmão, } \\
\text { I. de C. }\end{array}$ & \begin{tabular}{lr}
\multicolumn{2}{l}{ Risco ocupacional dos } \\
profissionais \\
enfermagem frente ao \\
atendimento \\
pacientes \\
diagnóstico \\
tuberculose
\end{tabular} & $\begin{array}{c}\text { Revisão } \\
\text { narrativa da } \\
\text { literatura }\end{array}$ & $\begin{array}{l}\text { fica evidente a necessidade de promover educação } \\
\text { em saúde incentivando o uso correto dos EPI's, } \\
\text { assim como garantir por meio das políticas de } \\
\text { saúde a disponibilização de EPI's corretos em } \\
\text { quantidade suficiente afim de minimizar o risco } \\
\text { ocupacional. }\end{array}$ \\
\hline
\end{tabular}

Fonte: Autores (2021).

Oliveira et al (2019) conceitua a qualidade de vida no trabalho (QVT) como se fosse um programa que visa facilitar e satisfazer as necessidades do trabalhador desenvolvendo suas atividades na organização, com o objetivo principal com base no que os colaboradores são mais produtivos quando percebem que estão seguros e sentem satisfação naquilo que estão fazendo dentro do próprio trabalho. É importante contemplar que, são muitos fatores que acabam contribuindo de forma direta para a qualidade do trabalho dos profissionais que trabalham na área hospitalar.

São muitos os fatores que provocam danos à saúde dos trabalhadores que atuam no ambiente hospitalar, pois dentro desse ambiente estar presente todos os tipos de riscos, (físico, químico, biológico, ergonômico e de acidentes). Todos eles, a longo e curto prazo, apresentam danos as vezes irreversíveis a saúde desse trabalhador. Alguns fatores que contribui para a esses agravos são: ausência de EPIs, materiais humanos as vezes desqualificados, instrumento de trabalho inadequados, carga horária de trabalho excessiva sem descanso devido, estrutura física apresentando falha etc (Gregório, 2017).

A saúde no trabalho funciona como uma estratégia importante não somente para proporcionar a saúde dos trabalhadores, é essencial para proporcionar ao trabalhador a alcançar uma realização pessoal e profissional, sendo determinante para aumentar e melhorar a qualidade em relação a produtividade (Silva; Valente; Camacho, 2020). Para se ter maiores e melhores resultados no âmbito dos serviços ofertados em saúde, os mesmos devem vislumbrar todo contexto envolvido nesse processo, considerando que, os agentes envolvidos na prestação do cuidar devem ser assegurados de condições que the proporcione realizar os serviços de forma digna. Assim, os serviços de saúde, devem, ter suas bases administrativas e gerenciais embasadas, a partir de três recortes: a biossegurança, a saúde do trabalhador e a promoção de condições de ofertar os serviços com qualidade (Hokeberg et al., 2006).

É exatamente nesse caminho que os profissionais que trabalham na saúde precisam ter a sua disposição elementos que proporcione a eles segurança, através de equipamentos novos e adequados as suas necessidades, uma quantidade maior de funcionários, ambiente harmonioso e adequado, iluminação adequada, materiais de trabalho diversos, equipamentos de proteção individual, dessa forma, ter condições que garantam o desenvolvimento de um trabalho eficaz (Lopes et al., 2020). A seguir, a Quadro 2 com a identificação dos riscos ambientais, presente nos ambientes de trabalho em saúde. 
Quadro 2 - Riscos ambientais presente nos ambientes de trabalho.

\begin{tabular}{|c|c|c|l|}
\hline Grupo & Riscos & $\begin{array}{c}\text { Cor de } \\
\text { Identificação }\end{array}$ & \multicolumn{1}{|c|}{ Descrição } \\
\hline 1 & Físicos & Verde & $\begin{array}{l}\text { Ruído, calor, frio, pressões, umidade, radiações } \\
\text { ionizantes e não ionizantes, vibrações, etc. }\end{array}$ \\
\hline 2 & Químicos & Vermeiho & $\begin{array}{l}\text { Poeiras, fumos, gases, vapores, névoas, neblinas, } \\
\text { etc. }\end{array}$ \\
\hline 3 & Biológicos & Marron & $\begin{array}{l}\text { Fungos, vírus, parasitas, bactérias, protozoários, } \\
\text { insetos, etc. }\end{array}$ \\
\hline 4 & Ergonômicos & Amarela & $\begin{array}{l}\text { Levantamento e transporte manual de peso, } \\
\text { monotonia, repetitividade, responsabilidade, ritmo } \\
\text { excessivo, posturas inadequadas de trabalho, } \\
\text { trabalho em turnos, etc. }\end{array}$ \\
\hline 5 & Acidentais & Azul & $\begin{array}{l}\text { Arranjo fisico inadequado, iluminação inadequada, } \\
\text { incêndio e explosão, eletricidade, máquinas e } \\
\text { equipamentos sem proteção, quedas e animais } \\
\text { peçonhentos. }\end{array}$ \\
\hline
\end{tabular}

Fonte: Hokeberg et al. (2006).

Os riscos que são encontrados nos ambientes laborais podem ser entendidos: riscos físicos, químicos, biológicos, ergonômico e os acidentes de trabalho. Salienta-se que, diante da exposição direta aos riscos ocupacionais acima, estes atuam como principais causadores dos acidentes de trabalho, já que de fato, no ambiente de trabalho, fatores como: tempo, exposição do trabalhador aos agentes causadores dos danos á saúde, práticas e hábitos incorretos dentro do ambiente de trabalho, são fatores que contribuem para o aumento dos índices de absenteísmo e dessa forma, refletindo negativamente na qualidade da assistência prestada (Marinho et al, 2018; Xavier; Gusmão, 2020; Oliveira; Andrade; Brock, 2017).

Para os profissionais que trabalham na área hospitalar, os riscos estão mais voltados para os acidentes com perfuro cortantes, principalmente nos procedimentos de punções venosa, nos testes de glicemia, na administração de medicações, nos procedimentos de curativos e suturas, nos descartes dos materiais na administração das vacinas, entre outros. Dentro dos riscos biológicos no ambiente hospitalar, destaca-se mencionar também quando os profissionais realizam o procedimento de exames Papanicolau e as consultas com os pacientes que tem doenças transmissíveis (Pustiglione, 2017; Ferreira et al., 2018).

Outro ponto a considerar, é as consequências que os danos à saúde resultam no ambiente hospitalar, tanto no que diz respeito ao aumento do número de absenteísmo, como a consequência disso na qualidade da assistência em saúde. A saber, absenteísmo, trata-se de um termo utilizado para designar a falta ou ausência do trabalhador ao local de trabalho. Ou seja, essa ausência pode ou não estar relacionada a doenças ou licenças médicas (Chiavenato, 1994).

Importante citar que nem sempre as causas de absenteísmo estão condicionadas ao trabalhador, muitas vezes, na maioria das vezes no que se refere aos ambientes hospitalares, principalmente os hospitais públicos, esses fatores se dar devido as condições de trabalho desfavoráveis, bem como a estrutura física precária e a repetitividade na realização das tarefas, que além de expor os trabalhos a riscos de trabalhos, também condicionam a desmotivação e desestímulos em relação ao trabalho (Silva; Marziale, 2000).

Percebe-se que diversos são as consequências advindas dos acidentes de trabalho, resultante dos riscos que os profissionais da saúde estão expostos. Percebe-se que, esses riscos estão em volta de todo ambiente hospitalar, expondo o trabalhador a riscos de ter ou desenvolver alguma doença, interferindo assim, na qualidade do trabalho realizado, resultando em má qualidade da assistência ofertada aos pacientes (Oliveira; Andrade; Brock, 2017).

Diante desse contexto e considerando que os riscos ambientais nos ambientes hospitalares, são fatores que nem sempre há como sanar. No entanto, em detrimento de fatores como a necessidade do emprego, alguns profissionais não têm 
uma percepção correta a respeito dos riscos à saúde nos ambientes de trabalho. Nesse enfoque, alguns profissionais, principalmente a equipe de enfermagem que representam um contingente maior no quadro de profissionais desse ambiente, não conseguem ter um olhar diferenciado em relação a sua segurança no trabalho, e acabam não levando em consideração os riscos ocupacionais. A convivência que ocorre no dia a dia com ambiente insalubre pode ainda enganar os trabalhadores quanto a importância de se adotar medidas preventivas para a sua própria segurança (Silva; Ferraz; Junior, 2016).

\section{Conclusão}

Os principais resultados encontrados puderam mostrar os riscos que os profissionais de saúde estão expostos nos locais de trabalho, ou seja, esse profissional está sujeito a adquirir ou desenvolver doenças de ordem física, química, biológica, ergonômica, e de acidentes. Ficando claro, que os trabalhadores que atuam no ambiente hospitalar, lidam diariamente com a exposição diária aos agentes causadores de adoecimento. Logo, os profissionais da enfermagem acabam sendo o público mais afetado, e consequentemente aquele que tem maiores chances de adquirir doenças especificas do trabalho, devido ser o profissional que lida diariamente com os pacientes.

Portanto, é necessário que seja feita a identificação antecipada dos riscos ocupacionais com o objetivo de minimizar a ocorrência de sinistros. Fazendo-se necessário a realização de treinamentos e educação continuada, visando orientar os profissionais de saúde, através dessas ações, os mesmos podem adquirir um melhor esclarecimento quanto aos riscos de acidentes ou de doenças ocupacionais, preservando a sua própria saúde e daqueles que estão a sua volta.

Por fim, é de fundamental importância que novos trabalhos relacionados a essa temática, sejam realizados, e dessa forma, trazer a luz uma problemática vivenciada pelos profissionais da saúde e quem nem sempre é exposta. Uma pesquisa de campo por exemplo, principalmente no período pandêmico, seria interessante, uma vez que devido ao aumento da demanda por procura em atendimento em saúde, acredita-se que houve também o aumento dos casos de acidentes de trabalho.

\section{Referências}

Arantes, M. C., Haddad, M. C. F. L., Marcon, S. S., Rossaneis, M. A., Pissinati, P. S. C., \& Oliveira, S. A. (2017). Acidentes de trabalho com material biológico em trabalhadores de serviços de saúde. Cogitare Enferm. 22(1): 01-08

Carmo, T. A., Tasso, C. A. S., \& Masson, V. A. (2016). Assistência de Enfermagem do Trabalho: Prevenção de Doenças Ocupacionais. Revista Ciência \& Inovação.

Carvalho, D. P. de., et al. (2017). Cargas de trabalho e a saúde do trabalhador de enfermagem: revisão integrativa. Cogitare Enferm.

Carrara, G. L. R., Magalhães, D. M., Lima., \& Catani, R. (2015). Riscos ocupacionais e os agravos à saúde dos profissionais de enfermagem. Revista Fafibe On-Line, Bebedouro SP, 8 (1): 265-286.

da Silva, S. L. (2021). Meio ambiente e segurança do trabalhador em enfermagem (Vol. 1). Difusão Editora.

Dias, C. V. P., Damasceno, J. C., Silva, L. V. F., \& Rocha, B. M. (2020). Saúde do profissional de Enfermagem: riscos ocupacionais em ambiente hospitalar. Revista Saúde (Sta. Maria).

Ferreira, A. P., et al. (2018). Revisão da literatura sobre os riscos do ambiente de trabalho quanto às condições laborais e o impacto na saúde do trabalhador. Rev Bras Med Trab;16(3):360-70.

Gil, A. C. (2019). Como Elaborar Projetos de Pesquisa. (6a ed.), Atlas.

Gomez, C. M., Vascocellos, L. C. F. de., \& Machado, J. M. H. (2018). Saúde do trabalhador: aspectos históricos, avanços e desafios no Sistema Único de Saúde. Ciência \& Saúde Coletiva.

Gregório, D. de S. (2017). Riscos Ocupacionais: Uma revisão da Literatura. Id on Line Rev. Psic. 11(34).

Hökerberg, Y. H. M. et al. (2006). O processo de construção de mapas de risco em um hospital. Revista Ciência e Saúde Coletiva. 11(2).

Leite, H. D. C. S., et al. (2016). Risco Ocupacional entre profissionais de saúde do Serviço de Atendimento Móvel de Urgência - SAMU. Enferm. Foco; 7 (3/4): 31-35.

Lopes, M. C., et al. (2020). Qualidade de vida de profissionais atuantes na área de reabilitação de um hospital escola no interior do Rio Grande do Sul. Rev. Interinst. Bras. Ter. Ocup. 4(4): 603-614. 
Research, Society and Development, v. 10, n. 15, e486101523089, 2021

(CC BY 4.0) | ISSN 2525-3409 | DOI: http://dx.doi.org/10.33448/rsd-v10i15.23089

Marinho, T. A., et al. (2018). Gestão de Riscos à Saúde do Trabalhador: Uma Abordagem Problematizadora na Formação em Vigilância em Saúde. Revista Eletrônica Gestão \& Saúde.

Mendes, V. L. P. S., \& Aguiar, F. C. (2017). Implementação da política de saúde pública e seus desafios na era digital. Revista de Administração Pública|Rio de Janeiro 51(6):1104-1121.

Oliveira, M. M., Andrade, N. V. De., \& Brock, J. (2017). Riscos ocupacionais e suas repercussões nos profissionais de enfermagem no âmbito hospitalar. Revista Enfermagem Contemporânea. Outubrol;6(2):129-138.

Oliveira, L. de A. M., et al. (2019). Risco ocupacional em profissionais médicos e enfermeiros de unidade de terapia intensiva e suas influências na qualidade de vida: uma revisão narrativa. Brazilian Journal of Surgery and Clinical Research - BJSCR. 28(4), 82-87.

Pereira, J. P. de M., Nóbrega, W. F. S., \& Paiva, R. E. dos A. (2019). Doenças ocupacionais em profissionais da enfermagem: uma revisão integrativa. Arch Health Invest 8(11).

Pustiglione, M. A (2017). segurança (e saúde) do trabalhador da saúde e a segurança do paciente: uma análise do impacto das ações de segurança e saúde no trabalho em serviços de saúde. Revista de Administração em Saúde.

Silva, A., Ferraz, L., \& Junior, S. A. R. (2016). Ações em Saúde do Trabalhador desenvolvidas na Atenção Primária no município de Chapecó, Santa Catarina. Revista Brasileira de Saúde Ocupacional.

Silva, R. P., Valente, G. S. C., \& Camacho, A. C. L. F. (2020). O gerenciamento de risco no âmbito da saúde de profissionais de enfermagem no contexto hospitalar. Rev Bras Enferm. 73(6): e20190303.

Silva, D. M. P. P. D., \& Marziale, M. H. P. (2000). Absenteísmo de trabalhadores de enfermagem em um hospital universitário. Revista latino-americana de enfermagem, $8,44-51$.

Silvério, F. C. de M., \& Moraes, R. S. de. (2020). Enfermeiro do trabalho: prevenção de riscos ergonômicos. Enfermagem Revista 23(1).

Vasconcellos, L. C. F. de., \& Aguiar, L. (2017). Saúde do Trabalhador: necessidades desconsideradas pela gestão do Sistema Único de Saúde. Saúde Debate.

Xavier, E. K. M., \& Gusmão, I. de C. (2020). Risco ocupacional dos profissionais de enfermagem frente ao atendimento de pacientes com diagnóstico de tuberculose. Trabalho de conclusão de curso. Goiânia - GO. 